\title{
Seasonality and Frequency of Snake and Goanna Incursions on an Australian Agricultural Institute and the Attitudes of Staff Regarding Coexistence
}

\author{
Matthew Mo \\ P.O. Box A290, Sydney South, New South Wales 2000, Australia (matthew.sk.mo@gmail.com)
}

Photographs by the author.

\begin{abstract}
A number of snakes and goannas persist in areas frequented by humans, such as the Elizabeth Macarthur Agricultural Institute in New South Wales, Australia. This institute is used as both an office location and an agricultural demonstration site, which inevitably results in snakes and goannas coming close to institute buildings, prompting concerns for human safety. Reports of snakes and goannas within $100 \mathrm{~m}$ of institute buildings were collected over a threeyear period; an analysis of those data identified a seasonal pattern of incursions by three species between September and March. A short verbal survey revealed that more staff had encountered goannas than snakes. Most were cautious to curious when snakes and goannas were reported, whereas only a minority admitted to being fearful when snakes were reported.
\end{abstract}

$\mathrm{H}$ uman interactions with wildlife are complex. Interactions can be positive when wildlife is valued for either aesthetical, cultural, economic, or functional reasons (Orams 2002; Wilkinson et al. 2014; Mo and Waterhouse 2015a). Conversely, conflicts arise from social, cultural, economic, political, or even environmental factors (Barker et al. 2008; McClelland et al. 2011; White and Ward 2011). Reptiles are among the least favored vertebrates (Ceriaco 2012; Abell 2013). Members of the general public tend to be more accommodating toward coexistence with mammals, birds, and fish than reptiles. For example, urban communities in Australia develop overwhelming attachments to local populations of iconic species such as the Koala (Phascolarctos cinereus; e.g., Ward and Close 2004; Lunney et al. 2010) and Powerful Owl (Ninox strenua; e.g., McNabb et al. 2007; Mo and Waterhouse 2015b). On the contrary, a common response to reptiles is a desire to have them removed, with licensed handlers able to generate some income from relocating them (Shine and Koenig 2001).

In Australia, a number of front-fanged venomous snakes (family Elapidae) and goannas (family Varanidae) have persisted in frequently-used areas (Butler et al. 2005; Shea 2010). The Elizabeth Macarthur Agricultural Institute (EMAI), situated in Menangle, New South Wales, is an example of a wellused facility vulnerable to incursions of snakes and goannas.
Herein, I report on the seasonality and frequency of snake and goanna incursions close to institute buildings, and the results of a short verbal survey that gauged attitudes of institute staff regarding co-existence with snakes and goannas.

\section{Methods}

The EMAI is part of a 1,600-ha property approximately 70 $\mathrm{km}$ southwest of the Sydney central business district (Fig. 1).
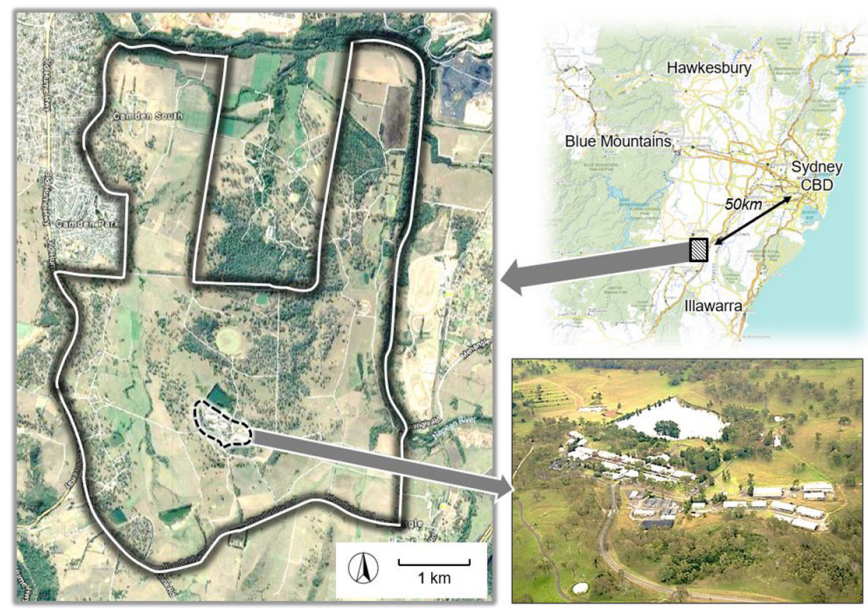

Fig. 1. Layout of the Elizabeth Macarthur Agricultural Institute and its location within the Sydney region. 
Owned by the New South Wales Department of Primary Industries since 1990, the property has been used as both a departmental office location and an agricultural demonstration site. The landscape is a mosaic of open woodland remnants and livestock paddocks on gently undulating terrain situated between the Nepean River and the Razor Back Range (Starr et al. 2004; Mo 2017, 2018). Large permanent dams have been established to provide water in addition to ephemeral floodplains. Vegetation restoration has been progressively implemented to create conservation corridors throughout the property. The institute buildings occupy 11 ha of the EMAI property and are situated south of a large permanent dam. The juxtapositioning of the institute buildings and agricultural land had led to staff encounters with wildlife, which has raised health and safety concerns. European Rabbit (Oryctolagus cuniculus) warrens are common on the property, particularly in the immediate vicinity of buildings (Fig. 2). These warrens provide retreat sites for other species, including reptiles.

I collected data on snake and goanna sightings within $100 \mathrm{~m}$ of institute buildings at EMAI between February 2014 and February 2017, during the time when I had an office at

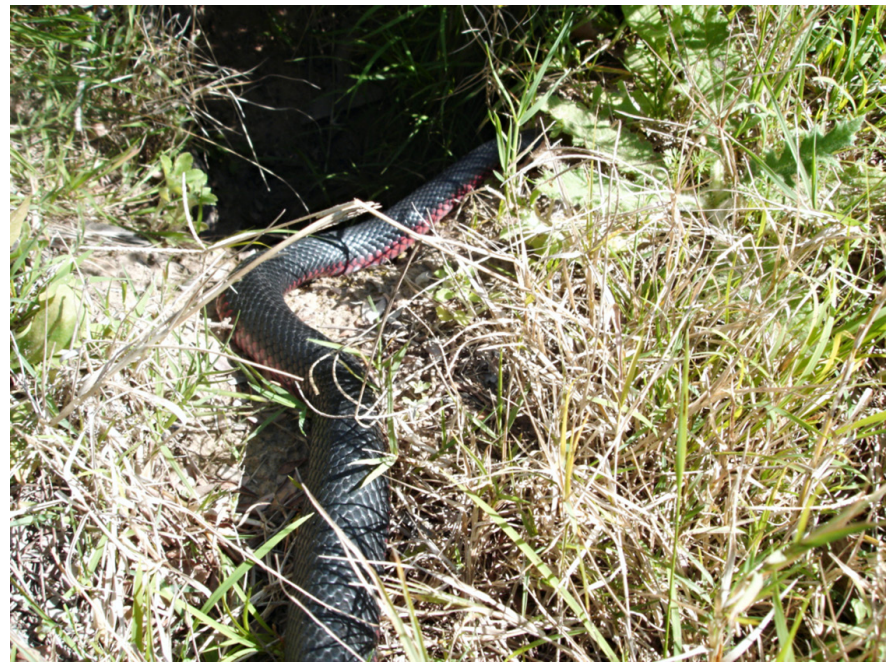

Fig. 2. A Red-bellied Black Snake (Pseudechis porphyriacus) descending into a rabbit warren.

the site. Sightings were primarily gathered by reports from institute staff, either reported to reception or me directly. Reporting wildlife sightings to the institute reception had

Table 1. Questions that formed the semi-structured survey on the attitudes of institute staff toward snakes and goannas.

\section{Question}

Has the participant seen a snake on the institute grounds?

\begin{tabular}{rc}
\hline No & $\square$
\end{tabular}
Response range

$\square$ Yes

\begin{tabular}{ll}
\hline How does the participant feel when they hear a snake has been sighted? & $\square$ Afraid \\
\hline & $\square \quad$ Wary, but not afraid \\
$\square \quad$ Curious, but not concerned \\
$\square \quad$ Not curious or concerned
\end{tabular}

\begin{tabular}{lc}
\hline What is the participant's ideal standing in relation to snakes on the institute grounds? & Never want to see them \\
\hline & Don't mind seeing them \\
\hline Want to see them
\end{tabular}

Has the participant seen a goanna on the institute grounds?

$\square$ Yes

\begin{tabular}{rr} 
No \\
\hline
\end{tabular}

How does the participant feel when they hear a goanna has been sighted?

What is the participant's ideal standing in relation to goannas on the institute grounds?

\begin{tabular}{ll}
$\square$ & Afraid \\
$\square$ & Wary, but not afraid \\
$\square$ & Curious, but not concerned \\
$\square$ & Not curious or concerned \\
\hline
\end{tabular}

\begin{tabular}{rr}
\hline What is the participant's ideal standing in relation to goannas on the institute grounds? & $\square \quad$ Never want to see them \\
\hline & $\square$ Won't mind seeing them \\
\hline
\end{tabular}


been a long-running practice intended for circulating precautionary notifications to staff. These reported sightings tended to be biased toward animals found directly outside institute buildings and potentially hazardous species, such as snakes, goannas, and swooping birds. Where possible, details on the behavior of the snake or goanna were obtained, as well as the duration it remained close to institute buildings. No sightings were considered repeated observations of the same individual, although that possibility is likely.

I conducted short verbal surveys to examine the perceptions of institute staff toward snakes and goannas at EMAI. These surveys comprised six questions (Table 1), ranging from whether the respondent had personally seen either snakes or goannas to how they felt about the presence of these reptiles at the site. Participants ranged in residence from local to the Macarthur region to visiting from the metropolitan areas of the Sydney, Illawarra, and Shoalhaven regions.

\section{Results}

Reports of snakes and goannas near institute buildings were strongly seasonal, mostly confined to the months of September to March (Table 2). The highest encounter rates were in the months of September, October, and November, which is spring in the Southern Hemisphere. The Lace Monitor (Varanus varius; Fig. 3) was the most frequently reported species, and reports were usually of foraging individuals. Typical behaviors observed included scanning by turning the head from side to side, tongue-flicking, and stopand-start or investigative movements. Actual predation was

Table 2. Monthly distribution of reports of three species near institute buildings. Percentages for each species are shown in parentheses.

\begin{tabular}{lccc} 
Month & $\begin{array}{c}\text { Red-bellied } \\
\text { Black Snake }\end{array}$ & $\begin{array}{c}\text { Eastern } \\
\text { Brown Snake }\end{array}$ & $\begin{array}{c}\text { Lace } \\
\text { Monitor }\end{array}$ \\
\hline January & $1(2.1)$ & $1(9.1)$ & $8(9.2)$ \\
\hline February & $4(8.5)$ & $2(18.2)$ & $14(16.1)$ \\
\hline March & $13(27.7)$ & $1(9.1)$ & $1(1.1)$ \\
\hline April & $1(2.1)$ & 0 & 0 \\
\hline May & 0 & 0 & 0 \\
\hline June & 0 & 0 & 0 \\
\hline July & 0 & 0 & 0 \\
\hline August & $1(2.1)$ & 0 & 0 \\
\hline September & $12(25.5)$ & $3(27.3)$ & $17(19.5)$ \\
\hline October & $6(12.8)$ & $2(18.2)$ & $21(24.1)$ \\
\hline November & $5(10.6)$ & $1(9.1)$ & $19(21.8)$ \\
\hline December & $4(8.5)$ & $1(9.1)$ & $7(8.0)$ \\
\hline & & & \\
\hline Total & $\mathbf{4 7}$ & $\mathbf{1 1}$ & $\mathbf{8 7}$ \\
\hline
\end{tabular}

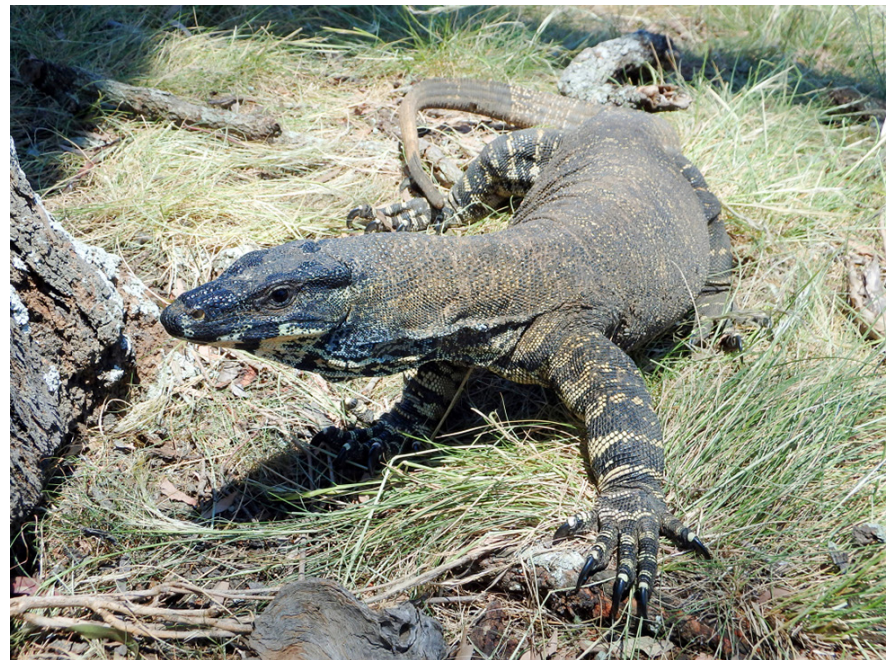

Fig. 3. A Lace Monitor (Varanus varius) that had recently fed on a large food item, which rendered it unable to move away quickly from the author.

observed on Noisy Miner (Manorina melanocephala) chicks that had dropped from the nest on two occasions, as well as two unsuccessful pursuits of rabbit kittens. Goannas also entered rabbit warrens; however, whether they were retreating in response to disturbance or hunting was not clear. No goannas were habituated to humans, with the most approachable individuals allowing humans to advance to only about $20 \mathrm{~m}$ before fleeing. One exception was a large goanna that had recently gorged on a large food item. This animal was subsequently unable to move swiftly or support itself on a tree trunk.

The most frequently reported snake was the Redbellied Black Snake (Pseudechis porphyriacus; Fig. 4), which was encountered most frequently in March and September (Table 2). More than 80 percent of sightings were snakes basking within $10 \mathrm{~m}$ of rabbit warrens, with three individuals retreating down warrens in response to disturbance. The

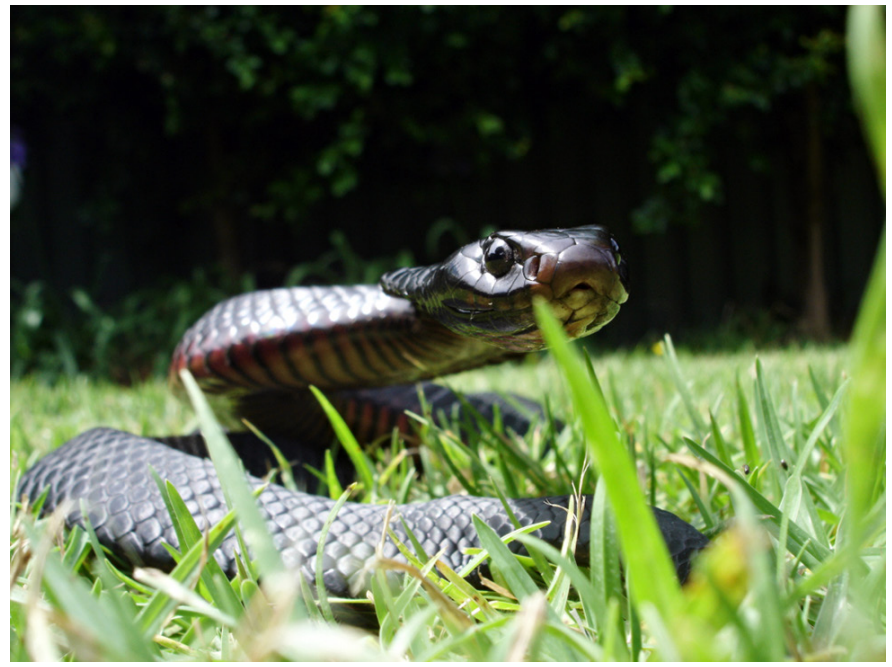

Fig. 4. A Red-bellied Black Snake (Pseudechis porphyriacus) reacting to human traffic nearby. 


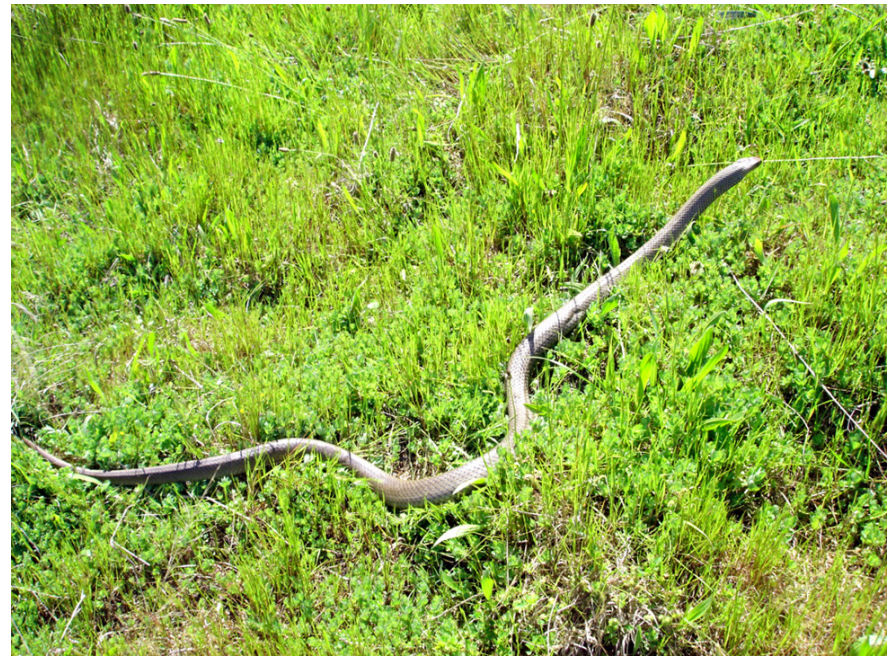

Fig. 5. An Eastern Brown Snake (Pseudonaja textilis) moving across a sheep paddock.

only incident of a snake actually entering a building during the study period was a juvenile Red-bellied Black Snake. The remaining snake sightings were attributed to Eastern Brown Snakes (Pseudonaja textilis; Fig. 5). Unlike the Redbellied Black Snake, this species was less likely to move away when approached. One individual could be approached to within $1 \mathrm{~m}$ by people who had not noticed it until they were in close proximity. A third large elapid, the Mainland Tiger Snake (Notechis scutatus) had been reported by staff in the past but was not recorded during the study period. The Red-naped Snake (Furina diadema) and Blackish Blindsnake (Ramphotyphlops nigrescens) were encountered in surrounding paddocks under surface debris moved by farm workers and bush regenerators (M. Mo, unpubl. data). However, none of these observations were within $100 \mathrm{~m}$ of institute buildings and hence not included in Table 2.

The survey results showed that more participants had encountered goannas near institute buildings than snakes (Table 3). The most common reaction to receiving reports of snakes was to be wary of their presence. A minority of participants admitted to being afraid, whereas just more than a fifth reacted with curiosity. Approximately one quarter of participants were largely unaffected by snake reports. Goanna reports also elicited wariness in most participants; however, no participants reported being afraid. The proportion of participants who became curious in response to goanna reports was the same as for snake reports. Fewer participants were impartial to hearing of goannas than snakes. The majority of participants were comfortable seeing goannas on the institute grounds, in contrast to just more than half of participants that preferred to not see any snakes. However, slightly more participants actually wanted to see snakes on the institute grounds than goannas.

\section{Discussion}

More survey participants had encountered goannas than snakes, which correlated with goannas being recorded near institute buildings more frequently than snakes during the study period. This is probably a function of goannas being more conspicuous than snakes, and their presence often being heralded by mobbing birds, such as the Noisy Miner (e.g., Cunningham and Magrath 2017).

Despite being broadly feared, only a minority of reptilian species can actually threaten human safety (Pough et al. 1998). In this study, more survey participants feared snakes than goannas. Fears may arise from perceived or actual dan-

Table 3. Numbers of survey participants whose experience and opinions aligned with eight positions on snakes and goannas at the institute site. Percentages of participants are shown in parentheses.

Position

Snakes

Goannas

Personal experiences

Have seen them on the institute grounds

$34(68)$

$47(94)$

\section{Reactions to receiving reports}

\begin{tabular}{lcc}
\hline Afraid when hearing they have been sighted & $3(6)$ & 0 \\
\hline Wary but not afraid when hearing they have been sighted & $24(48)$ & $33(66)$ \\
\hline Curious, but not concerned when hearing they have been sighted & $11(22)$ & $11(22)$ \\
\hline Neither curious nor concerned when hearing they have sighted & $12(24)$ & $6(12)$ \\
\hline
\end{tabular}

\section{Personal preferences}

\begin{tabular}{lcc}
\hline Prefer not to see them on the institute grounds & $27(54)$ & 0 \\
\hline Don't mind seeing them on the institute grounds & $14(28)$ & $45(90)$ \\
\hline Want to see them on the institute grounds & $9(18)$ & $5(10)$ \\
\hline
\end{tabular}


gers (Cariaco et al. 2012), animal phobias (Agras et al. 1969; Ahs et al. 2009), or emotional and cultural issues (Knight 2008). Safety concerns regarding venomous snakes are particularly relevant at the study site since the Eastern Brown Snake is a leading cause of snake bite fatality in Australia (White 2000). Nevertheless, this species comprised the minority of snakes reported in this study, and the risks of human-snake interaction were mitigated by implementing site management practices, such as mowing grass and reducing debris, and by encouraging personal safety precautions. This study showed that the presence of snakes and goannas near institute buildings followed defined seasonal patterns. This serves as a benefit for safety management by providing the opportunity for staff to become more vigilant at certain times of year.

The capacity for reptile conservation on the property relies on the willingness of staff to coexist with snakes and goannas and for site management to mitigate risks to human safety. The survey results indicated that although goanna sightings elicited wariness in most staff, their presence at the study site was unanimously accepted. On the other hand, although only a minority of staff were actually afraid when snakes were reported, slightly more than half of respondents preferred not to encounter them. The survey, however, did not clearly distinguish between preferring not to see snakes from being unwilling to coexist with snakes. Consequently, staff might prefer to not encounter snakes but still desire for some snakes to occur within the broader property.

\section{Acknowledgements}

I thank present and past EMAI staff for relaying information.

\section{Literature Cited}

Abell, J. 2013. Volunteering to help conserve endangered species: An identity approach to human-animal relationships. Journal of Community and Applied Social Psychology 23: 157-170.

Agras, S., D. Sylvester, and D. Oliveau. 1969. The epidemiology of common fears and phobias. Comprehensive Psychiatry 10: 151-156.

Ahs, F., A. Pissiota, A. Michelgard, O. Frans, T. Furmark, L. Appel, and M. Fredrikson. 2009. Disentangling the web of fear: Amygdala reactivity and functional connectivity in spider and snake phobia. Psychiatry Research 172: 103-108.

Barker, P.J., L. Boitani, S. Harris, G. Saunders, and P.C.L. White. 2008. Terrestrial carnivores and human food production: Impact and management. Mammal Review 38: 123-166.

Butler, H., B. Malone, and N. Clemann. 2005. Activity patterns and habitat preferences of translocated and resident Tiger Snakes (Notechis scutatus) in a suburban landscape. Wildlife Research 32: 157-163.

Ceriaco, L.M.P. 2012. Human attitudes towards herpetofauna: The influence of folklore and negative values on the conservation of amphibians and reptiles in Portugal. Journal of Ethnobiology and Ethnomedicine 8: 1-12.

Cunningham, S. and R.D. Magrath. 2017. Functionally referential alarm calls in Noisy Miners communicate about predator behaviour. Animal Behaviour 129: $171-179$.

Knight, A.J. 2008. "Bats, snakes and spiders, Oh my!" How aesthetic and negativistic attitudes, and other concepts predict support for species protection. Journal of Environmental Psychology 28: 94-103.

Lunney, D., R. Close, J.V. Bryant, M.S. Crowther, I. Shannon, K. Madden, and S. Ward. 2010. The Koalas of Campbelltown, south-western Sydney: Does their natural history foretell of an unnatural future? pp. 339-370. In: D. Lunney, P. Hutchings and D. Hochuli (eds.), The Natural History of Sydney. Royal Zoological Society of New South Wales, Mosman, NSW, Australia.

McClelland, K.L., P.J.S. Fleming, and P.J. Malcolm. 2011. Grey-headed Flyingfoxes in orchards: A collaborative project on damage estimates, contributing factors and mitigation strategies - triumphs and tribulations of flyingfox conservation and management in NSW, pp. 391-398. In: B. Law, P. Eby, D. Lunney and L. Lumsden (eds.), The Biology and Conservation of Australasian Bats. Royal Zoological Society of New South Wales, Mosman, NSW, Australia.

McNabb, E.G., R.P. Kavanagh, and S.A. Craig. 2007. Further observations on the breeding biology of the Powerful Owl Ninox strenua in south-eastern Australia. Corella 31: 6-9.

Mo, M. 2017. Killing of a mobbing Crested Pigeon Ocyphaps lophotes by an Australian Raven Corvus coronoides. Australian Field Ornithology 34: 35-36.

Mo, M. 2018. A survey for waterbirds on the Elizabeth Macarthur Agricultural Institute demonstration site, Menangle, New South Wales. Corella 42: 91-98.

Mo, M. and D.R. Waterhouse. 2015a. Historical insight on the Topknot Pigeon Lopholaimus antarcticus in the Illawarra rainforests through the 20th Century. Australian Zoologist 37: 337-342.

Mo, M. and D.R. Waterhouse. 2015b. Development of independence in Powerful Owl Ninox strenua fledglings in suburban Sydney. Australian Field Ornithology 32: 143-153.

Orams, M.B. 2002. Feeding wildlife as a tourism attraction: A review of issues and impacts. Tourism Management 23: 281-293.

Plough, F.H., R.M. Andrews, J.E. Cadle, M.L. Crump, A.H. Savitzky, and K.D. Wells. 1998. Herpetology. Prentice-Hall, Upper Saddle River, New Jersey.

Shea, G.M. 2010. The suburban terrestrial reptile fauna of Sydney — winners and losers, pp. 154-197. In: D. Lunney, E. Hutchings, and D. Hochuli (eds.), The Natural History of Sydney. Royal Zoological Society of New South Wales, Mosman, NSW, Australia.

Shine, R. and J. Koenig. 2001. Snakes in the garden: An analysis of reptiles "rescued" by community-based wildlife carers. Biological Conservation 102: 271-283.

Starr, M., M.J. Starr, and S.C. Wilson. 2004. Raptor populations at an agricultural site featuring sustainable farming practices near Sydney, New South Wales. Australian Field Ornithology 21: 67-71.

Ward, S. and R. Close. 2004. Southern Sydney's urban Koalas: Community research and education at Campbelltown, pp. 44-55. In: D. Lunney and S. Burgin (eds.), Urban Wildlife: More than Meets the Eye. Royal Zoological Society of New South Wales, Mosman, NSW, Australia.

White, J. 2000. Why do people still die from brown-snake bites? Emergency Medicine 12: 204-206.

White, P.C.L. and A.I. Ward. 2011. Interdisciplinary approaches for the management of existing and emerging human-wildlife conflicts. Wildlife Research 37: 623-629.

Wilkinson, C., G. Waitt, and L. Gibbs. 2014. Understanding place as 'home' and 'away' through the practices of bird-watching. Australian Geographer 45: 205-220. 